\title{
水みち状流れによる吸着性物質の移動特性： 確率論的ネットワークモデルをもちいて
}

\author{
杉田 文
}

\section{Sorptive Solute Transport in a Channelized Flow System: Application of a stochastic channel network model}

\author{
Fumi Sugita
}

\begin{abstract}
Sorptive solute transport through channelized flow regimes was investigated using a two-dimensional channel network model. Channel networks of various geometry were generated stochastically and sorptive as well as non-sorptive solute transports in the media were simulated. The sorption reaction was assumed to become equilibrium instantaneously and to have a linear and singular isotherm. Breakthrough curves (BTCs) in actual concentration and time were normalized by total tracer concentration and by an average discharge time of non-sorptive tracer from the network. These normalized BTCs indicate distinctive characteristics of sorptive solute transport in the heterogeneous media such that: (1) The medium with smaller average channel size gives delayed breakthrough and greater spreading in sorptive solute BTCs, whereas non-sorptive solute BTCs are not affected by average channel size, since BTCs are normalized (2) When average channel size is the same, a medium which has wider channel size variation gives significantly greater spreading in sorptive solute BTCs whereas non-sorptive solute BTCs show only slight increase in BTC spreading (3) As channel density increases, difference in effects of channel size variation on nonsorptive and sorptive solute BTCs becomes small (4) BTC characteristics are not significantly affected by channel orientation nor by variation in channel orientation, although permeability of the network is affected by the orientation of the channels. The second and the third results indicate that sorptive solute transport exhibits more pronounced effect of heterogeneity in the discrete media than non-sorptive solute transport does. It also suggests that medium with greater heterogeneity causes larger spreading in sorptive solute BTCs, which may lead to considerably early arrival of the solute to a certain point of ques.
\end{abstract}


tion in a field situation.

key words: channel network, sorption, stochastic model, heterogeneity

\section{1. はじめに}

多孔体と異なり透水性の比較的低い周結岩盤に 㧍ける水㧍よび物質の動きは放射性廃棄物やその 他の有毒廃液等の隔離処分といった問題から近年 特に注目をあびるようになった。岩盤内の水の流 れは亀裂が高密度に発達しているなどある特殊な 条件下では多孔体内のそれと同様に一様流として 扱うことができる(Long et al.、1982など)。しか し多くの野外や室内に㧍けるトレーサー実験は岩 盤内における水の流れが非常に不均一であること を示し、不連続的な水みち状の流れとして扱う必 要性を示唆している(Dverstorp et al.、1992)。

不均一な水みち状流れが生じる原因は、岩盤全 体といった大スケールでは亀裂の存在によるもの で、単一亀裂のような小スケールでは亀裂内の水 みちの発達によるものである。このうち大スケー ルの不均一な流れ場は亀裂ネットワークモデルに より有効にモデル化されることがよく知られてい る。初期の多くのネットワークモデルでは各亀裂 内の流れを一組の平行板内の流れと見なせると仮 定していた(Schwartz et al.、1983など)。しかし 単一亀裂を用いた室内実験 (Neretnieks et al. 1982)や野外実験にネットワークモデルを応用し た研究 (Cacas et al、1990a、b、Dverstorp et al、 1992)では単一亀裂内においても水みちが発達し 不均一な流れが卓越していることが指摘された。 そして、このような水みちの発達は物質移動に特 に強い影響を与えることが示された(Dverstorp $e t$ al. 1992)。

Moreno et al. (1988) は確率論に基づいた粗面を 持つ単一龟裂モデルを用いて単一亀裂内で水みち 状流れが卓越することを示した。Tsang et al. (1988)は亀裂内の水みちを統計的に等価な一次元 の流れとしてモデル化することを提案し、Moreno et al. (1988)の二次元モデルと流出曲線の計算 結果においてよい一致を示した。彼らのモデルで は分子搪散、テイラーの分散(Taylor、1953)のほ
か水みちから基岩への物質の拡散などを考慮して いなかった。そこでJohns \& Roberts(1991)は比 較的大きい水みち内の物質移動をより微細な亀裂 部分および基岩への拡散を考慮しながら解析的に 解き、水みち状流れに扮いては水と基岩との接触 面積が少ないため基岩への拡散は物質移動に大き な影響を与えない一方、微細な龟裂部分への拡散 は大きな影響を与える可能性が強いことを示し た。

多くの放射性物質を用いた室内実験(Moreno et al.1985、Neretnieks et al.、1982など)ではトレー サーが岩盤表面と吸着反応を起こすことが報告さ れているが、以上のいずれのモデルでも物質の吸 着反応はあまり考虑されていない。そこで本研究 では統計值に基づき確率的に発生させた互いに連 結した水みちのネットワークを用いてトレーサー 移行に関する数值シミュレーションを行い、不連 続的流れ場における吸着を伴う污染物質の移動特 性ついて検討することを目的とした。多くの有毒 物質の環境中における許容濃度は非常に低い。し たがって地中におけるそれら污染物質の移動を考 える時、ある特定地点への平均到達時間よりも極 低濃度による初期到達時間の予測が重要な課題と なる。この初期到達時間は物質の平均移動速度ば かりではなく広がり、つまり分散の度合いに大き く左右されると考えられる。そこで本研究ではと くに分散の度合いに重点を招きながら吸着反応の 影響について考察を行った。

\section{2. 水みちモデルの概要}

本研究で用いた二次元水みちネットワークモデ ルは多孔体を微視的にモデル化した間隙モデル (Sugita et al.、印刷中)を基礎としてその一部を 水みちを表現するように改良したものである。全 体の計算手順は以下の様である。

(1)二次元の解析領域内に与えられた数の水み ちの中心点を任意に選ぶ。 
(2)各中心点に対して水みちの長さ、径、主動 水勾配方向からの角度をそれぞれのパラメー ターに与えられた分布関数から独立に任意に 選び、水みちのネットワークを構築する。様々 な種類の亀裂性岩盤の調査から一般に岩盤中 の亀裂の幅(径)は対数正規分布をもつとされ ている(Snow、1970)。そこで本解析では径 は対数正規分布を持つとし、平均径および標 準偏差の二つの統計值を入力パラメーターと した。長さは、本解析ではネットワーク構築 時の入力值としては均一とした。しかし、一 本の水みちが水や物質輸送に実際に寄与する 有效長は他の水みちとの交点の位置や流出入 境界との連続性により異なってくるため、最 終的には個々の水みちはそれぞれ異なる長さ を持つことになる。実際の岩盤中における水 みちの角度は一般的にはいくつかの似た方向 性をもつグループに分けられるといわれてい る。本解析では水みちは二つのグループから なるとし、それぞれのグループは比較的狭い 角度範囲において正規分布をもつと仮定して それぞれに異なる統計值を与えた。個々の水 みちの径や角度はそれぞれに与えられた分布 関数に基ずいて互いに独立にランダムに抽出 した值とした。

(3)流出入境界から不連続であったり行き止ま りになる水みち、また解析領域からはみだし た水みちを取り除く。

(4)構築されたネットワークを数值計算のため 小さい要素に分割する。各要素の分割点は節 点と呼ばれる。水みちの各交点を節点とする ほか交点間、即ち単一水みちも数值計算上の 必要に応じてより小さい一次元要素に分割す る。

(5)流れ場 (水頭)について与えられた外部境界 条件(一定水頭または不透水)に基づき、ガ ラーキン法に基づいた有限要素法により解 く。水みち内の一次元定常流の連続の式は次 のように表せる。

$$
\frac{\partial}{\partial l}\left(K_{l} \frac{\partial h}{\partial l}\right)=0
$$

$\mathrm{h}$ は水頭、1は線形要素に沿った距離、 $\mathrm{K}_{1}$ は
透水係数で各水みちを完全円筒形とすると次 式で与えられる(例えば、Daugherty \& Franzini、1977)。

$K_{l}=\frac{\rho g b^{2}}{8 \mu}$

$\rho$ は流体密度、gは重力加速度、 $\mu$ は流体粘 性係数、bは水みちの半径である。本研究で は解析領域を一这 $10 \mathrm{~cm}$ の正方形とし、上下 境界は不透水、左右の境界は一定水頭值を持 つとした。

（6）(5)で解いた流れ場に基ついて物質移動に ついて非吸着性物質、吸着性物質の順に粒子 追跡法 (Kinzelbach、1986)により解く。すな わち、上流境界に多数の同一濃度を代表する トレーサー粒子を放出すると各粒子は(5)で 得られた流れ場およびローカルな遅延係数 (R)の值に従ってネットワーク内を移動し下 流境界から流出する。一つの時間ステップご との粒子の移動は次式により表せる (Kinzelbach、1986)。

$$
\begin{aligned}
& l_{p}(t+\Delta t)= \\
& \quad l_{p}(t)+\frac{V(l(t), t)}{R} \Delta t+N(0,1) \sqrt{2 \frac{D}{R} \Delta t}
\end{aligned}
$$

ここで $1 \mathrm{p}$ は線形要素に沿った粒子の位置、 $\mathrm{t}$ は時間、 $\mathrm{V}$ は水流速、 $\mathrm{R}$ は遅延係数、 $\mathrm{D}$ は 分散係数、 $\mathrm{N}(0 、 1)$ は平均 0 、標準偏差 1 の正規分布をもつランダム変数である。本研 究では分配係数は解析領域内で均一であり、 吸着は可逆反応で瞬時にして平衡に達すると 仮定した。水みち中の分配係数 $\left(\mathrm{K}_{\mathrm{d}}\right)$ は単位 固体表面積に吸着された物質量と流体中の濃 度の比と定義されるため、各水みちの遅延係 数 $(\mathrm{R})$ は次式で表される。

$$
\begin{aligned}
& \begin{array}{l}
R=\text { unit surface area of a channel }(2 b \pi) \\
\text { unit volume of a channel }\left(\pi b^{2}\right)
\end{array} K_{d} \\
& R=1+\frac{2 K_{d}}{b}
\end{aligned}
$$

式(5)に従って全水みちは同一の分配係数を 
持つが、その径(b)の值により異なる遅延係 数をもつことになる。本解析では水みちの交 点で完全混合が起こると仮定したため、ある 交点に到達した粒子は過去の履歴に依らず単 純に各水みちの流量の比に従った確率で次の 水みちへ進む。各粒子は等濃度トレーサーを 代表するので、粒子の放出時刻をゼロとする 時間軸に対して流出粒子数あるいは積算粒子 数をプロットすることにより流出曲線を得る ことができる。

間隙モデルと本モデルの主な相違点を次に示す。

(1)本モデルでは間隙モデルでは考慮されて いなかった水みち内での分散、すなわちテイ ラーの分散を物質移動ルーチンにとりいれ た。これは本解析では特に分散に注目してお り、水みち状流れではこの分散機構が溶質全 体の分散に大きな影響を与える可能性がある ためである。

(2)間隙モデルでは流路の密度は一定、角度は 二方向に限定されていたが、水みち状流れで はこれらの值にばらつきがあることが予測さ れるため、これらのばらつきを考慮した。

\section{3. 解析方法および解析結果}

\section{1 基本ケース入力值と解析手法}

基本ケースとして用いたシミュレーションの入 力值を表 1 に示す。本解析では全ての入力值セッ 卜に対してモンテカルロ的に10の流れ場を発生さ せてシミュレーションを行い、解析結果を検討す るためには単一シミュレーションの結果のほかそ れらのアンサンブル平均值をもちいた。基本ケー スとして発生させたネットワークの一例を図 1 に 示す。このネットワークの場合、孤立した水みち を除いた後の水みち総数は344、交点総数は1196、 流れおよび物質移動計算に用いた節点総数は 9240 となった。粒子追跡法に用いた総粒子数は400で ある。これは総粒子数2000個の場合から計算時間 節約のため流出曲線形状に大きな変化が現れない 範囲で徐々に個数を減らして決定した。

本解析ではトレーサーの流出曲線に対しては同 一ネットワークから得られた非吸着性物質の平均 流出時間が 1 となるように標準化・無次元化した 時間 $(\mathrm{T})$ を横軸に、全粒子が流出した場合が 1 と なるように標準化された濃度值を縦軸にとりプ ロットした。無次元化した時間 $(\mathrm{T})$ は次式で表せ る。

表 1 基本ケースの入力値

Table 1 Input parameters used for a reference case

\begin{tabular}{|c|c|c|}
\hline 各グループの水みち数 & $\begin{array}{c}\text { グループ } 1 \\
200\end{array}$ & $\begin{array}{c}\text { グループ } 2 \\
200\end{array}$ \\
\hline \multicolumn{3}{|l|}{ 主動水方向からの角度 } \\
\hline 分布関数 & 正規分布 & 正規分布 \\
\hline 平均 & $45^{\circ}$ & $-45^{\circ}$ \\
\hline 標準偏差 & $0^{\circ}$ & $0^{\circ}$ \\
\hline \multicolumn{3}{|l|}{ 径 } \\
\hline 分布関数 & 対数正規分布 & 対数正規分布 \\
\hline 平均 & $0.01 \mathrm{~cm}$ & $0.01 \mathrm{~cm}$ \\
\hline 標準偏差 & 0.1 & 0.1 \\
\hline 水みち長 & 均一 $2 \mathrm{~cm}$ & 均一 $2 \mathrm{~cm}$ \\
\hline 分子拡散係数 & \multicolumn{2}{|c|}{$1.61 \times 10^{-5} \mathrm{~cm}^{2} / \mathrm{sec}$} \\
\hline 分配係数 (Kd) & \multicolumn{2}{|c|}{$0.025 \mathrm{~cm}$} \\
\hline 平均動水勾配 & \multicolumn{2}{|c|}{0.1} \\
\hline 総粒子数 & \multicolumn{2}{|c|}{400} \\
\hline
\end{tabular}




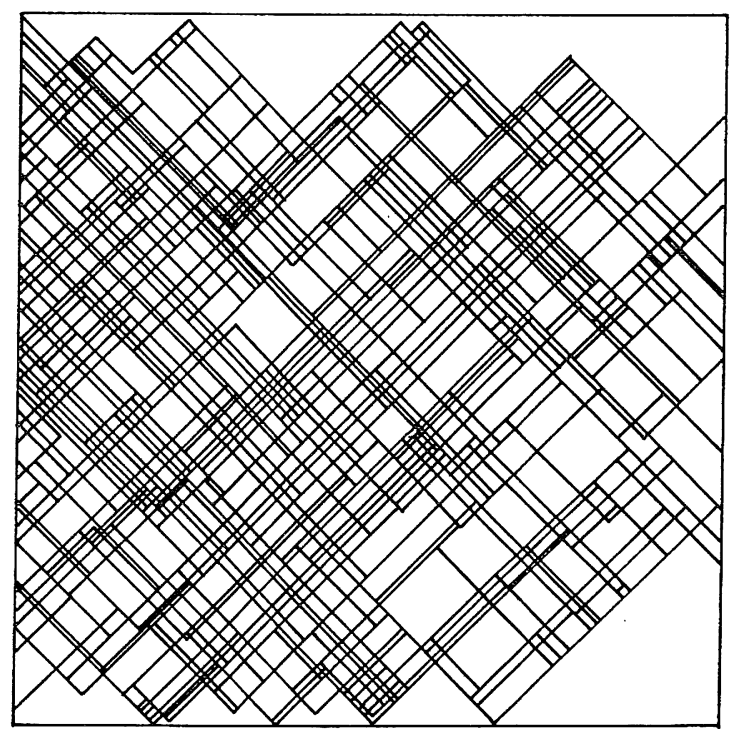

図1基本ケースとして発生させたネットワークの 例

Figure 1 A channel network generated as a reference case

$T=\frac{t}{t_{1}}$

ただし、

$t_{1}=\frac{\int_{0}^{\infty} t c(t) d t}{\int_{0}^{\infty} c(t) d t} d t$

ここで $\mathrm{t}$ は実時間、 $\mathrm{c}$ は非吸着性物質の濃度、 $\mathrm{t}_{1}$ は非吸着性物質の実時間における流出曲線の平均 流出時間(第一モーメント)である。分配係数 $(0.025 \mathrm{~cm})$ は砂に対して弱く吸着されるストロン チウムの分配係数にほぼ相当する。

流出曲線は時間に対して積算流出粒子数をプ ロットしたものであるが、解析においては時間に 対して単に流出粒子数をプロットした曲線(流出 曲線を一，回微分した曲線）、C、のモーメントを 求めることによりその特性を数值化することを試 みた。第一モーメント $\left(\mathrm{M}_{1}\right)$ は次式によって定義 され、時間軸上における流出曲線の中心位置、す なわち平均流出時間を示す。

$M_{1}=\frac{\int_{0}^{\infty} T C(T) d T}{\int_{0}^{\infty} C(T) d T}$
第二モーメント $\left(\mathrm{M}_{2}\right)$ の平方根 (STD) は曲線の 広がり示し次式で与えられる。

$\operatorname{STD}=\left(M_{2}\right)^{\frac{1}{2}}=\left(\frac{\int_{0}^{\infty}\left(T-M_{1}\right)^{2} C(T) d T}{\int_{0}^{\infty} C(T) d T}\right)^{\frac{1}{2}}$

第二モーメント $\left(\mathrm{M}_{2}\right)$ の三乗と第三モーメント $\left(\mathrm{M}_{3}\right)$ の二乗の比 $(\mathrm{SKW})$ は曲線の歪みを表し、0 の場合曲線の中心軸に関して左右対象、正の場合 は急激な立上りと長い尾を持つ方向に、そして負 の場合は緩やかな立上りで短い尾を持つ方向に曲 線が歪んでいることを示す。第三モーメント $\left(\mathrm{M}_{3}\right)$ および歪み(SKW) はそれぞれ(10)式、(11)式で 定義される。

$M_{3}=\frac{\int_{0}^{\infty}\left(T-M_{1}\right)^{3} C(T) d T}{\int_{0}^{\infty} C(T) d T}$
$S K W=\frac{M_{3}^{2}}{M_{2}^{3}}$

基本ケースから水みちの径、角度および総数など を独立に変化させて各パラメーターが流出曲線に 与える影響を調査した。

\section{2 平均径および径のばらつき}

水みちの平均径を変化させた場合の流出曲線の 典型例を図 2 に示す。平均径の変化のみの影響を 観察するため、示された 3 例の水みちの幾何学構 造は同一のものである。非吸着性物質の流出曲線 は自身の第一モーメントで標準化された場合平均 径変化の影響を全く受けない。一方、吸着反応を 伴う場合平均径が大きいものほど流出時間が早く なることがわかる。これは遅延係数が水みちの体 積と表面積の比の関数であるためである。すなわ ち大きい径の水みち程小さい遅延係数をもつため 吸着性物質の移動速度は速く、小さい径の水みち ほど逆に遅延係数が大きくなるため、吸着性物質 の移動速度が遅くなるためである。他の 9 例の水 みちネットワークにおけるシミュレーションも同 様の結果を示した。

10のシミュレーションのモーメント特性のアン サンブル平均值を表 2 にまとめた。吸着性物質の 平均流出時間を表す第一モーメントが平均径が小 さくなるにつれ大きくなり、流出時間が径の小さ いものほど遅れることを示している。一方、広が 
りを表す標準偏差も非吸着性物質では何れの平均 径でもほとんど変化しないが吸着性物質では径が 小さくなるにつれ大きくなっており分散の度合い も大きくなることがわかる。吸着性物質のSTD をM 1 で除した值は、均一な多孔体における理 論では、平均径(媒体の透水性)に依存せず、非吸 着性物質のSTD と等しくなることが知られてい る。得られたSTD/M 1 は平均径に依存はしない が、常に非吸着性物質のSTDより大きい值をと ることがわかる。これは、多孔体には存在しない ネットワーク媒体の不均一性の影響と考えられ

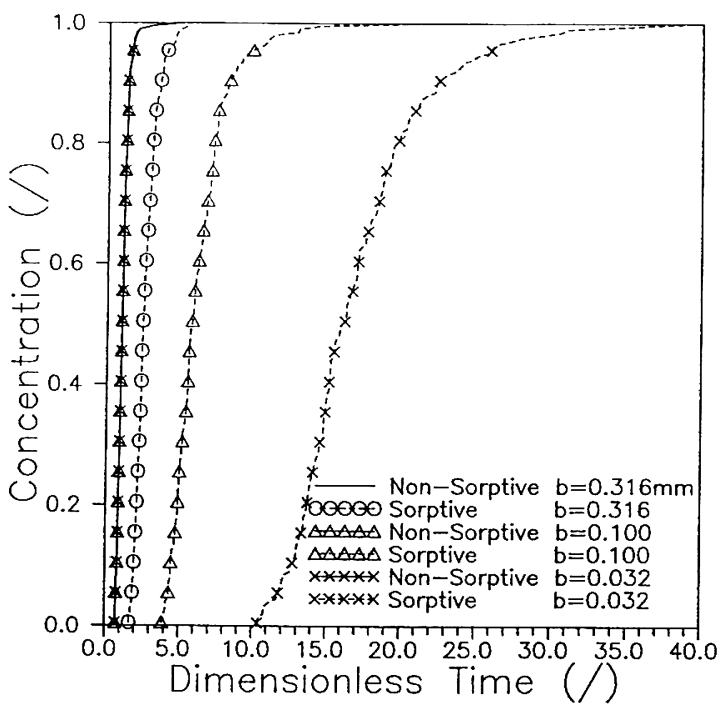

図2 異なる水みち平均径をもつネットワークから 得られたトレーサー流出曲線

Figure 2 Breakthrough curves obtained from networks with different mean channel aperture
る。歪みには特に顕著な平均径への依存性は見ら れなかった。上の結果から、吸着性物質の移動が 非吸着性物質のそれに比べて水みちの平均径の大 きさの影響を平均流出時間に強く受けることがわ かった。

次に闹一の平均径で径分布の標準偏差を0.0、 $0.1 、 0.2$ とし、媒体の不均一性を変化させた。得 られた流出曲線の一例を図 3 に示す。図 3 に示し た曲線を得たネットワークはいずれも同一の幾何 学構造を持ち、径分布の標準偏差の傎たけを変化 させたものである。平均径の值が同一なため平均

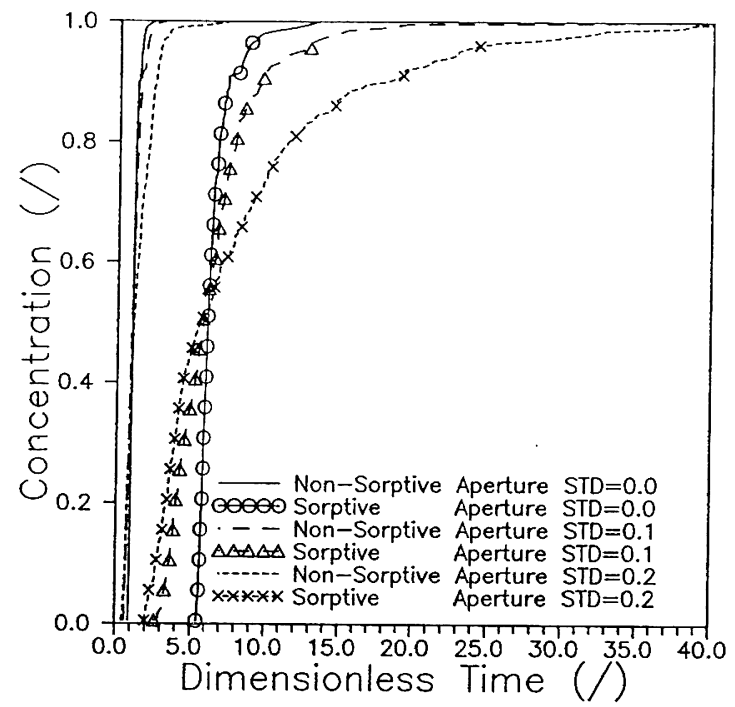

図 3 異なる水みち分布をもつネットワークから得 られた流出曲線

Figure 3 Breakthrough curves obtained from networks with different channel aperture distribution

表 2 異なる平均径をもつ水みちネットワークから得られた流出曲線の形状特性

(M 1 : 平均流出時間、STD：標準偏差、SKW：歪み)

Table 2 Ensemble averages of breakthrough curve properties: three different mean channel apertures (M 1 : average discharge time, STD: standard deviation, SKW: skewness)

\begin{tabular}{llcccccc}
\hline \multirow{2}{*}{ 平均径 $(\mathrm{mm})$} & \multicolumn{3}{c}{ 非吸着性物質 } & \multicolumn{4}{c}{ 吸着性物質 } \\
& M 1 & STD & SKW & M 1 & STD & SKW & STD/M 1 \\
0.316 & 1.00 & 0.15 & 1.01 & 2.39 & 0.51 & 1.61 & 0.21 \\
0.100 & 1.00 & 0.15 & 1.48 & 5.57 & 1.07 & 0.94 & 0.19 \\
0.032 & 1.00 & 0.17 & 1.33 & 15.75 & 3.45 & 0.94 & 0.22 \\
\hline
\end{tabular}


的流出時間(濃度 $\fallingdotseq 0.5$ の流出時間)に大きな差は 認められない。一方、非吸着性・吸着性物質共に 径のばらつきが大きい場合ほど曲線の広がりが大 きくなり、その傾向は吸着性物質の流出曲線でよ り顕著であることがわかる。特に、吸着性物質の 流出曲線の初期流出時閒が大きく影響を受けてお り、径のばらつきが増すにつれて非常に早い時間 に流出を開始することがわかる。水みちの径が均 一なほど領域内における水の流速のばらつきが小 さくなるためにトレーサーの分散が小さくなり、 逆に不均一になるほど流速のばらつきが大きくな りトレーサーの分散が大きくなるため、水みち径 の標準偏差は非吸着性・吸着性物質両者の移動に 影響を与えていると考えられる。吸着性物質にお いては、水流速の遅い小さい水みちは大きい遅延 係数を持つため吸着性物質の移行速度はさらに遅 くなるのに対し、水流速の速い大きい水みちは小 さい遅延係数をもつために吸着性物質の移行速度 は相対的にさらに速くなる。このメカニズムのた め、移行速度分布のばらつきは吸着性物質では非 吸着性物質のそれよりさらに助長されて大きくな り、曲線の広がり、すなわち分散が大きくなった と考えられる。

モーメント特性のアンサンブル平均值を表 $3 に$ 示す。吸着性物質の平均流出時間にあまり大きな 変化は認められない。広がり (STD) は非吸着性・ 吸着性物質共に径の標準偏差、つまりばらつきが 増すにつれて大きくなっている。均一な媒体では 吸着性物質のSTDの值を第一モーメントの值で 除すると非吸着性物質のSTDの值になる。吸着 性物質のSTD/M 1 の值も表 3 に示した。径の標 準偏差が $0.0 、 つ ま り$ 均一径の時は非吸着性物質
のSTD 值とほぼ等しくなるが、1.0、2.0と径の ばらつきが増加にともなって非吸着性物質の STDに比べ大きな值となることがわかる。した がって非吸着性物質のSTD と比較しても、多孔 体中とは異なり、径のばらつきが大きくなるにつ れ吸着性物質のSTDがより強い影響を受けて大 きくなっていることがわかる。

歪み (SKW) は径の標準偏差が0.1の時に最小で その前後で大きくなっている。これは径が単一の 時は一斉に物質の流出が開始され、流出曲線の立 上りが非常に急なのに比し、尾の部分が長引いて いるため歪みが大きくなり、標準偏差が 0.20 場 合はむしろ尾の部分が長引いているために曲線の 歪みの值が大きくなっていることが図 3 からわか る。以上の結果から水みち径のばらつきの影響は 吸着性物質のほうがより強くその広がりに受ける ことが認められた。

\section{3 水みちの密度}

水みちの総数を $200 、 400 、 750$ と変化させるこ とによりその密度が流出曲線に与える影響を調べ た。水みち総数が200と750の場合のネットワーク の例を図 $4(\mathrm{a}$ と b) に示す。図 $4 \mathrm{a}$ と b 例では 不連続な水みちを取り除いた後の有効水みち数は 160 と 695、また交点総数はそれぞれ351および 4219である。すなわち後者の方が水みち数にして 約4.3倍、交点数にして約12.0倍水みち密度が高 い媒体となっている。流出曲線の一例を図 5 に示 した。非吸着性・吸着性物質ともに水みち密度の 低い媒体ほど曲線の広がりが大きく長い尾をもつ ことがわかる。その影響は吸着性物質でより顕著 である。流出開始時間には大きな変化は認められ

\section{表 3 同一平均径で異なる標準偏差の水みち径分布もつネットワークから得られた流出曲線の形状特性 (M 1 ： 平均流出時間、STD：標準偏差、SKW：歪み)}

Table 3 Ensemble averages of breakthrough curve properties: three different channel aperture distributions (M 1, STD and SKW are the same as in Table 2)

\begin{tabular}{cccccccc} 
径の標準偏差(/) & \multicolumn{3}{c}{ 非吸着性物質 } & \multicolumn{4}{c}{ 吸着性物質 } \\
& M 1 & STD & SKW & M 1 & STD & SKW & STD/M 1 \\
0.0 & 1.0 & 0.07 & 7.18 & 6.00 & 0.38 & 9.70 & 0.06 \\
1.0 & 1.0 & 0.15 & 1.48 & 5.57 & 1.07 & 0.93 & 0.19 \\
2.0 & 1.0 & 0.28 & 2.24 & 5.19 & 2.20 & 8.39 & 0.42
\end{tabular}



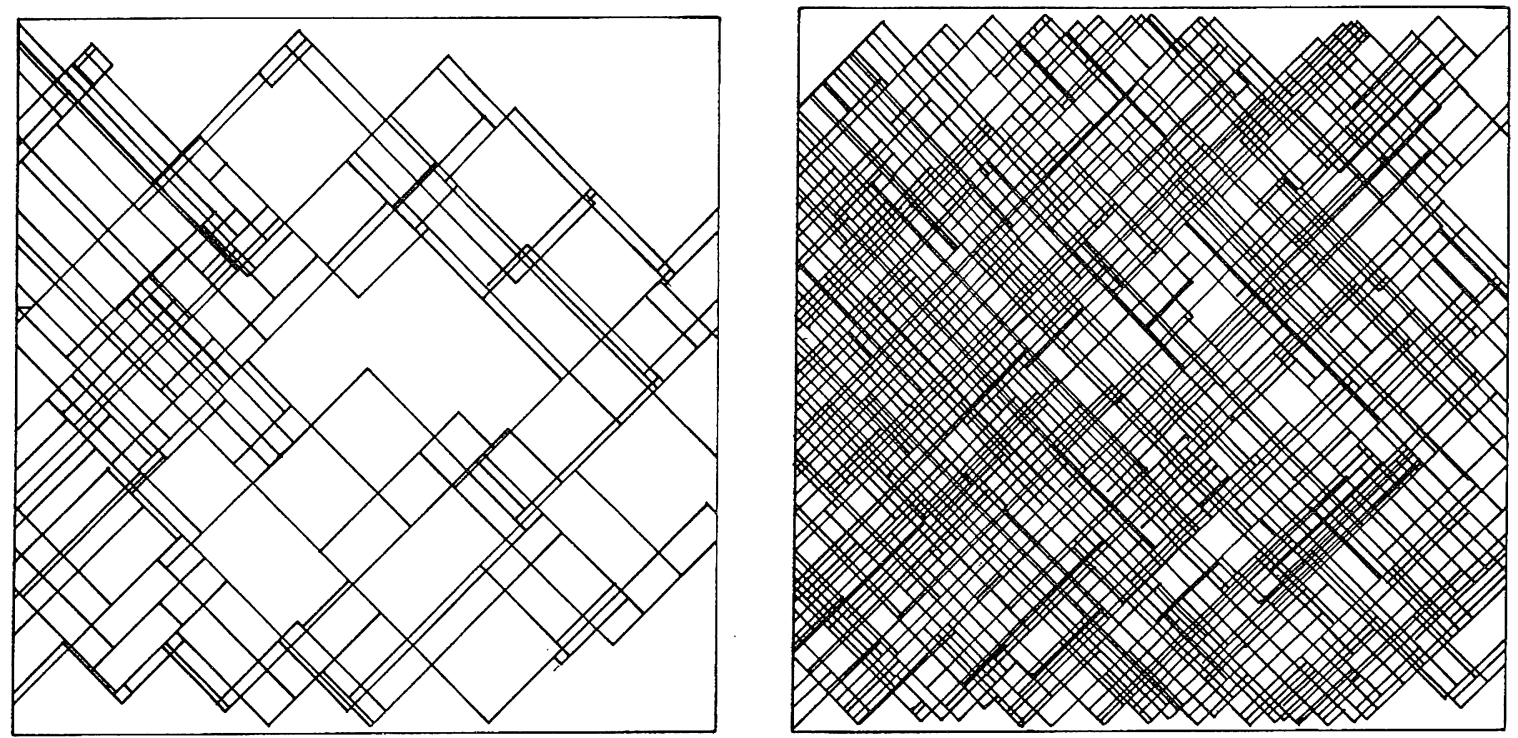

図4 異なる水みち密度をもつネットワークの例

(a：入力水みち総数 $200 \mathrm{~b}$ : 入力水みち総数 750)

Figure 4 Networks of (a) sparse and (b) dense channel densities

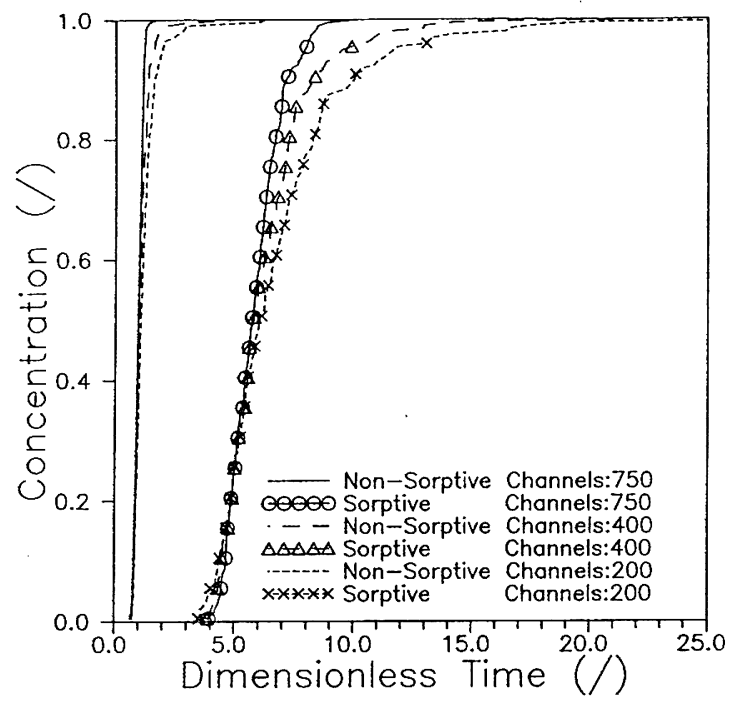

図 5 異なる水みち密度をもつネットワークから得 られた流出曲線

Figure 5 Breakthrough curves obtained from different channel density

ない。流出特性に関する10のアンサンブル平均值 を表 4 に示す。水みち密度の増加は媒体の透水係 数と直接的に結び付いてそのアンサンブル平均は
200、400、750の時にそれぞれ0.261、0.807、 $2.021 \mathrm{~cm} / \mathrm{min}$ となった。吸着性物質の平均流出時 間に密度変化に伴う変化は見られず、 $\mathrm{STD}$ (標準 偏差)およびSKW(歪み)の值は媒体の水みち密度 が高まるほど小さい值をとる。すなわち水みち密 度が高くなるほど流出曲線の広がりが小さくな り、左右対象になることを示している。連続性媒 体である多孔体では、平衡吸着条件下において吸 着性物質のSTD/M 1 の值は非吸着性物質のSTD の值と等しくなり、SKWは０に近い值をとる。 本モデルにおいても、最も密度が高く連続性のよ い場合では非吸着性物質のSTD と吸着性物質の STD/M 1 の值が接近し、SKW 值は 0 に近づくこ とが分かる。このことは、水みち密度が高く連続 性がよければ吸着反応による流出曲線に対する特 異な影響は小さくなり一般多孔体と闰様に非吸 着・吸着性物質を扱えることを示唆している。

\section{4 水みちの方向性}

亀裂表面にランダムな凹凸がある場合や規則的 あるいは方向性を持つ凹凹がある場合などその表 面の性状および充填物質の有無、また動水勾配方 向と凹凸の方向性の角度差などにより水みちの方 
向性にも違いが生じることが予測される。そのよ うな水みちの主方向と動水勾配の方向との違いや 水みち方向のばらつきが物質移動に与える影響を 調査した。

基本ケースでは水みち角度のばらつき(標準偏 差)は0であったが標準偏差が10度および20度の 場合の計算を行なった。発生させた媒体の例を図 $6(\mathrm{a}$ と b) に示す。図 6 の例では有効水みち数は 10 度の場合で 351,20 度で356、交点数は 10 度が 1421,20度が1510であり連続性に大きな違いはな い。これらの媒体から得られた流出曲線の例を図
7 に示した。非吸着性物質では20度の場合に少し 長めの尾が認められるものの曲線の形状にほとん ど角度のばらつきの影響は見られない。吸着性物 質においてはばらつきが全く無い場合に比べて10 度の場合は曲線がより急激に立ち上がって広がり がわずかではあるが小さくなる。20度の場合は逆 にやはりわずかではあるがより早い流出とより長 い尾が認められ広がりが多少大きくなっているこ とがわかる。いずれにしても形状変化はあまり顕 著ではない。流出開始時間にもほとんど差はみら れなかった。

表 4 異なる水みち密度をもつネットワークから得られた流出曲線の形状特性

(M 1 : 平均流出時間、STD : 標準偏差、SKW : 歪み)

Table 4 Ensemble averages of breakthrough curve properties: three different aperture densities $(M 1$, STD and SKW are the same as in Table 2)

\begin{tabular}{|c|c|c|c|c|c|c|c|c|c|}
\hline \multirow{2}{*}{$\begin{array}{l}\text { 水みち数 } \\
\text { (入力値) }\end{array}$} & \multirow[t]{2}{*}{ 交点数 } & \multirow{2}{*}{$\begin{array}{l}\text { 透水係数 } \\
(\mathrm{cm} / \mathrm{min})\end{array}$} & \multicolumn{3}{|c|}{ 非吸着性物質 } & \multicolumn{4}{|c|}{ 吸着性物質 } \\
\hline & & & M 1 & STD & SKW & M 1 & STD & SKW & $\mathrm{STD} / \mathrm{M} 1$ \\
\hline 200 & 4293 & 0.26 & 1.0 & 0.21 & 8.42 & 6.38 & 1.84 & 3.25 & 0.29 \\
\hline 400 & 1270 & 0.81 & 1.0 & 0.15 & 1.48 & 5.57 & 1.07 & 0.93 & 0.19 \\
\hline 750 & 334 & 2.02 & 1.0 & 0.08 & 0.20 & 5.61 & 0.66 & 0.37 & 0.11 \\
\hline
\end{tabular}
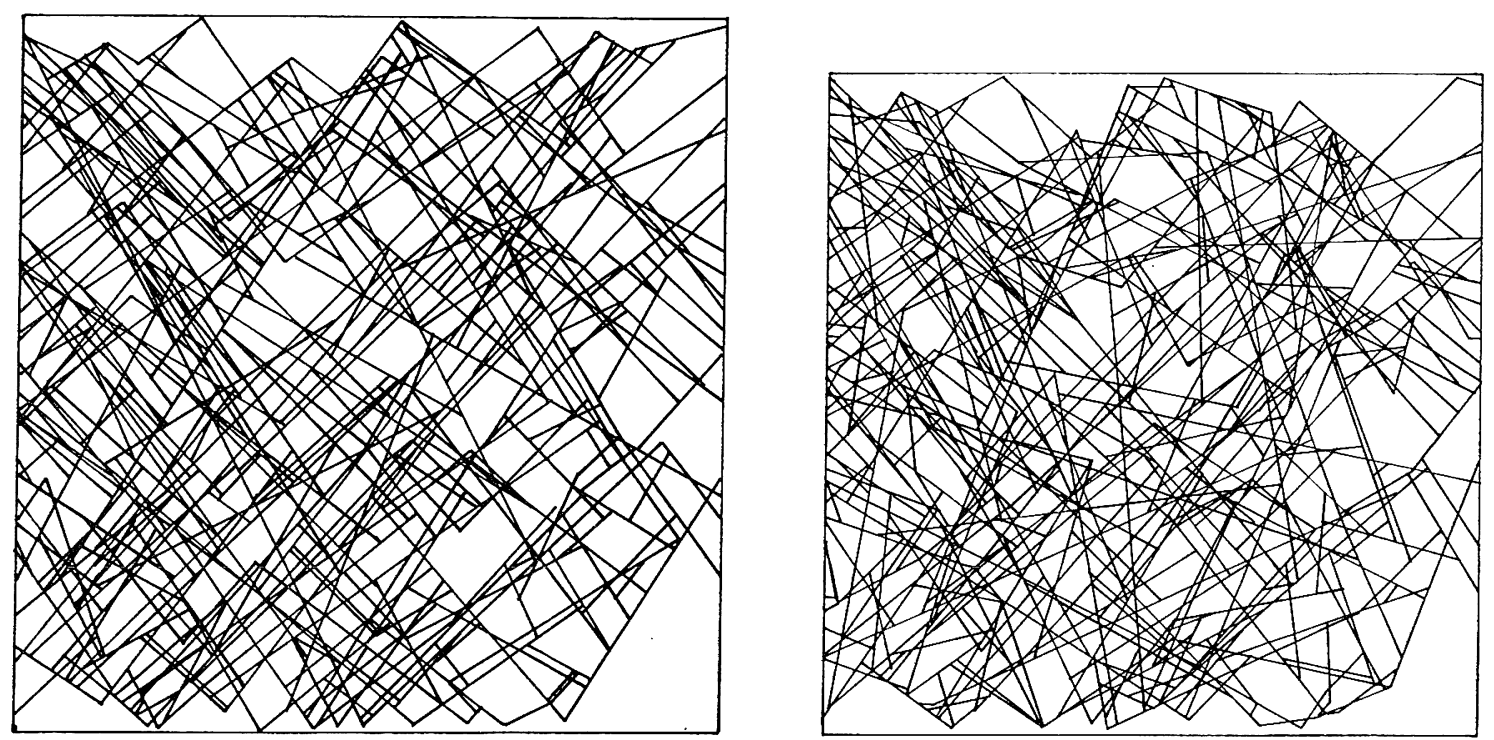

図 6 水みちの方向にばらつきがある場合のネットワークの発生例

(平均 $\pm 45^{\circ}$ 、標準偏差 $\mathrm{a}: 10^{\circ} 、 \mathrm{~b}: 20^{\circ}$ )

Figure 6 Networks of different channel angle distributions (mean $\pm 45^{\circ}$, STD a: $10^{\circ}, \mathrm{b}: 20^{\circ}$ ) 


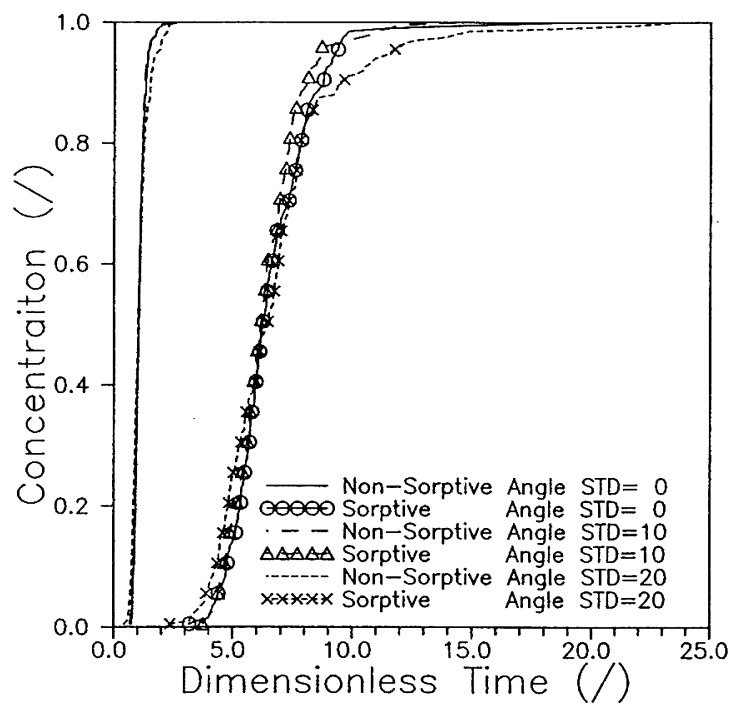

図7異なる水みち方向特性をもつネットワークか ら得られた流出曲線

(主動水勾配からの平均角度士 $45^{\circ}$ )

Figure 7 Breakthrough curves obtained from different channel angle distribution (mean angle $\pm 45^{\circ}$ )

流出曲線の形状特性をまとめたものを表 5 上段 (土45度)に示す。アンサンブル平均においてもい ずれの特性值にも標準編差の増加に伴う大きな変 化や系統的変化は見られない。吸着性物質の STD 值は標準偏差が10のとき最小になる。角度 のばらつきが 0 の時に比べ10度の時は交点数が大 幅に増えているため媒体の連続性がよくなり速度
のばらつきが小さくなり、STDが小さくなった と推定される。更に流路方向のばらつきが大きく なると交点数はあまり变化しないが流路が複雑に なるため、移行速度のばらつきが大きくなって STD が増加したと考えられる。

次に水みちの主方向を動水勾配の主方向( 0 度) または直交方问(90度)とし、そのばらつきを $0 、$ 10度㧍よび20度と変化させた。100シミュレー ション結果のアンサンブル平均值を表 5 下段 ( 0 、 90度)に示してある。水みちの主方向が $0 、 90$ 度 の場合、士45度の場合に比べ、透水係数の值は大 きくなる。これは水みちの主方向の一つが流れの 上流と下流を直接的に結び付ける方向に一致する ことにより透水性が高くなったためと考えられ る。また標準偏差が 0 の場合に限ってみると流出 曲線の分散を表すSTDが、0、90度の場合士45 度の場合に比べて大きくなっている。これは水み ちの主方向の一つ( 0 度)が流れの上下流を直接的 に結び付けて流速の速い流路を提供する一方、も う一つの主方向(90度)が動水勾配と直角となり極 端に流速の遅い流路を形成して総合的にネット ワーク内での流速のばらつきが大きくなったため と考えられる。主方向の違いによるSTDの值の 差は方向のばらつきが増加するのに伴い小さくな り、標準偏差が20度の場合にはSTDの值は主方 向によらずほぼ等しくなっている。

そのほか主流方向が土45度の時には標準偏差の 増加に伴う交点数の増加により、透水係数が増加 したが、0、90度の場合には交点数の増加に伴う

\section{表 5 異なる水みちの方向特性をもつネットワークから得られた流出曲線の形状特性}

(M1：平均流出時間、STD：標準偏差、SKW：歪み)

Table 5 Ensemble averages of breakthrough curve properties: three different channel angle distributions (M1, STD and SKW are the same as in Table 2)

\begin{tabular}{|c|c|c|c|c|c|c|c|c|c|}
\hline \multirow{2}{*}{$\begin{array}{l}\text { 平均 } \\
\text { (度) }\end{array}$} & \multirow[t]{2}{*}{ 標準偏差 } & \multirow[t]{2}{*}{ 交点数 } & \multirow{2}{*}{$\begin{array}{c}\text { 透水係数 } \\
\mathrm{cm} / \mathrm{min}\end{array}$} & \multicolumn{3}{|c|}{ 非吸着性物質 } & \multicolumn{3}{|c|}{ 吸着性物質 } \\
\hline & & & & M 1 & STD & SKW & M 1 & STD & SKW \\
\hline \multirow[t]{3}{*}{ \pm 45} & 0 & 1270 & 0.72 & 1.0 & 0.15 & 1.48 & 5.57 & 1.07 & 0.93 \\
\hline & 10 & 1505 & 0.81 & 1.0 & 0.14 & 0.77 & 5.85 & 0.84 & 3.50 \\
\hline & 20 & 1610 & 0.83 & 1.0 & 0.22 & 0.60 & 5.64 & 1.12 & 2.60 \\
\hline \multirow[t]{3}{*}{0 と 90} & 0 & 1328 & 0.92 & 1.0 & 0.25 & 1.06 & 6.53 & 1.92 & 0.42 \\
\hline & 10 & 1551 & 0.92 & 1.0 & 0.23 & 1.06 & 5.75 & 1.73 & 0.97 \\
\hline & 20 & 1664 & 0.91 & 1.0 & 0.22 & 2.34 & 6.23 & 1.27 & 0.97 \\
\hline
\end{tabular}


透水係数の变化は見られなかった。したがって、 主流方向に水みちの主方向が一致している場合に は交点数のわずかな増加は全体の透水性に影響を 与えないことがわかった。

\section{4.まとめ}

不連続な水みち状流れによる物質移動特性につ いて水みちの二次元ネットワークモデルをもちい て調查した。さまざまな幾何学的統計値を持った 水みちモデルを確率論的に発生させ非吸着性・吸 着性物質を想定したトレーサー移行に関する数值 シミュレーションを行い流出曲線を算出した。吸 着反応は系内で一様かつ叮逆、瞬時にして平衡に 達すると仮定した。非吸着性物質の平均流出時間 により無次元化した時間に対してプロットされた 流出曲線の特性から次の結果を得た。(1)水みち の平均径の大きさは非吸着性物質の流出曲線の形 状には影響を与えないが、平均径が小さい場合ほ ど吸着性物質の平均流出時間は遅くなる。(2)水 みちの平均径が等しい場合、径の大きさのばらつ きは遅延係数にばらつきを生じさせるため、吸着 性物質の分散に顕著な影響を与える。径のばらつ きが大きい場合ほど、吸着性物質の流出曲線の分 散は非吸着性物質の分散に比べて大きくなる。吸 着性物質の流出開始時間は早くなり、長い期間流 出が続くようになる。（3）水みちの密度が低い場 合には吸着性物質の流出曲線は非吸着性物質に比 べ大きな分散と歪みを呈する。一方密度が高くな ると非吸着性・吸着性物質の流出曲線の分散・歪 みに見られた形状特性の違いは小さくなり多孔体 斿られる流出曲線の特性に近づく。(4)水み ちの主方向が動水勾配方向と一致すると透水性は 高くなる。一方、主方向からのばらつきの度合い は流出曲線に大きな影響を与えない。

（2）、（3）の結果は不連続的な流れ場では吸着性 物質の移動が非吸着性物質のそれに比べ媒体の不 均一性の影響をより強く受け、不均一性の存在は 吸着性物質の広がり(分散)を大きくすることを示 している。地下水中の溶存物質が大きな分散をお こすとその物質のある地点への初期到達時間が平 均到達時刻に比較し非常に早くなる。したがって、 吸着反応をおこす污染物質の亀裂中に㧍ける移動
予測などを行う際には流れ場の不均一性の影響を 考慮することが重要であることが示唆された。

\section{参 考 文 献}

Cacas,M.C., E.Ledoux, G.de Marsily, B.Tille, E.Durand, B.Feuga and P.Peaudecerf (1990a): Modeling fracture flow with a stochastic discrete fracture network: Calibration and validation 1 . The flow model. Water Resour. Res., 26(3), 479-489.

Cacas,M.C., E.Ledoux, G.de Marsily, A.Barbreau, P.Calmels, B.Gaillard and R.Margritta (1990b): Modeling fracture flow with a stochastic discrete fracture network: Calibration and validation 2. The transport model. Water Resour. Res., 26(3), 491-500.

Daugherty, R.L. and J.B. Framzini (1977): Fluid mechanics with engineering applicaitons. McGraw Hill, 564p.

Dverstorp,B., J.Andersson and W. Nordqvist (1992): Discrete fracture network interpretation of field tracer migration in sparsely fractured rock. Water Resour. Res., 28(9), 2327-2343.

Johns,R.A. and P.V.Roberts (1991): A solute transport model for channelized flow in a fracture. Water Resour. Res., 27(8), 1797-1808.

Kinzelbach,W. (1986): Groundwater Modelling: An introduction with sample programs in Basic. Elsevier Science Publishing Company Inc. 334p.

Long.J.C.S., J.S.Remer, C.R.Wilson and P.A.Witherspoon (1982): Porous media equivalents for networks of discontinuous fractures. Water Resour. Res., 18 (3), 645-658.

Moreno,L., I.Neretnieks and T. Eriksen (1985): Analysis of some laboratory tracer runs in natural fissures. Water Resour. Res., 21(7), 951-958.

Moreno,L., Y.W.Tsang, F.V.Hale and I.Neretnieks (1988) : Flow and tracer transport in a single fracture: $A$ stochastic model and its relation to some field observations. Water Resour. Res., 24(12), 2033-2048.

Neretnieks,I., T.Eriksen and P.Tahtinen (1982): Tracer movement in a single fissure in granitic rock: Some experimental results and their interpretation. Water Resour. Res., 18(4), 849-858.

Schwartz,F.W., L.Smith and A.S. Crowe (1983): A 
stochastic analysis of macroscopic dispersion in fractured media. Water Resour. Res., 19(5), 1253-1265.

Snow, D.T. (1970): The frequency and apertures of fractures in rock. Int. J. Rock Mech. Min. Sci., 7, 23-40.

Sugita, F., R.W. Gillham and C. Mase: Pore-scale variation in retardation factor as a cause of non-ideal breakthrough curves: II. Pore-network analysis. Water Resour. Res., (印刷中).
Taylor,G.I. (1953): Dispersion of soluble matter in solvent flowing slowly through a tube. Proc. Roy. Soc. A. 219, 186-203.

Tsang,Y.W., C.F.Tsang, I.Neretnieks and L.Moreno (1988): Flow and tracer transport in fractured media: A variable aperture channel model and its properties. Water Resour. Res., 24(12), 2049-2060.

(受付：1994年 3 月25日、受理：1994年12月21日) 